\title{
Arazi Kullanım Sınıfları İçin Farklı Kontrollü Sınıflandırma Algoritmalarının Karşılaştırılması
}

\author{
*Sinan BULUT ${ }^{1}$, Alkan GÜNLÜ ${ }^{1}$ \\ ${ }^{1}$ Çankırı Karatekin Üniversitesi, Orman Fakültesi, Orman Mühendisliği Bölümü, 18200, \\ ÇANKIRI \\ *Sorumlu yazar: sbulut@karatekin.edu.tr
}

Geliş Tarihi: 01.07.2016

\begin{abstract}
Özet
Bu çalışmanın amacı, Landsat 8 uydu görüntüsü kullanarak arazi kullanım sınıflarını farklı kontrollü sınıflandırma algoritmaları ile sınıflandırmak ve en uygun tekniği ortaya koymaktır. Bu amaçla, en yüksek olasılık (maksimum likelihood) ile destek vektör makineleri (DVM) için yaygın bir şekilde kullanılan doğrusal, polinom, radyal ve sigmoid kernel fonksiyonları kullanılmıştır. En iyi sonucu veren en yüksek olasılık metodu ile DVM polinom fonksiyonu çıktıları karşılaştırılmıştır. En yüksek olasılık metodu için kappa değeri ve genel sınıflandırma başarısı sırasıyla $0.81 \mathrm{ve} \% 85$ 'dir. DVM polinom fonksiyonu için ise bu değerler sırasıyla 0.79 ve \%84'tür. Ayrıca, her iki yöntemle sınıflandırılmış arazi kullanım sınıflarının konumsal analizi Coğrafi Bilgi Sistemleri kullanılarak yapılmıştır. Konumsal analiz sonuçlarına göre en yüksek olasılık metodu kullanılarak toplam alanın \%47.5'i, DVM polinom fonksiyonu ile \%43.3'ü doğru bir şekilde sınıflandırılmıştır.

Anahtar Kelimeler: Arazi kullanım sınıfları, En yüksek olasılık, Destek vektör makineleri, Landsat 8 uydu görüntüsü

Comparison of Different Supervised Classification Algorithms for Land Use Classes

Abstract

The aim of this study was to classify land use classes using Landsat 8 satellite image with different supervised classification algorithms and demonstrate the most proper technique. For this purpose, the highest probability (maximum likelihood) classification method and linear, polynomial, radial and sigmoid kernel functions for support vector machines (SVM) were used. The SVM method polynomial function and the maximum likelihood method which give better results were compared. The result showed that the maximum likelihood method was estimated with a 0.81 kappa statistic and $85 \%$ overall accuracy assessments, respectively. The SVM polynomial function for these values was 0.79 and $84 \%$. Spatial analysis of land use classes that were classified using both methods was also made by Geographical Information System. According to the spatial accuracy assessment results, $47.5 \%$ and $43.3 \%$ of total area were classified accurately by the maximum likelihood method and the SVM method, respectively.
\end{abstract}

Keywords: Land use classes, Maximum likelihood, Support Vector Machines, Landsat 8 satellite image

\section{Giriş}

Gelişen teknoloji, uydu sistemleri ve uygulamaya aktarılan yeni metotlar gün geçtikçe farklı ve derin boyutlar kazanmaktadır. Günümüzde uzaktan algılamanın konu olmadığı bilim dalları pek azdır. Özellikle ormancılık alanında yoğun bir kullanım alanı bulan uzaktan algılama sayesinde uydu görüntülerinin sinıflandırılması, meşcere parametrelerinin tahmini ve arazi yapılarının farklı formatlarda haritalara dökülmesi ile büyük ölçekli alanlar hakkında kolay bir şekilde ön bilgi elde edilebilmektedir. Yapılan bu işlemler için kullanılabilecek farklı teknikler bulunmaktadır. Uydu görüntülerinin sınıflandırılmasında kullanılacak pek çok algoritma mevcuttur. Destek vektör makineleri (DVM), en yüksek olasıllk, en yakın mesafe, mahalanobis siniflandirıcisı, yapay sinir ağları ve karar ağaçları bunlardan bazılarıdır (Otukei ve Blaschke, 2010; Srivastava ve ark., 2012; Taati ve ark., 2014; Üstüner ve ark., 2015; Kulkarni ve Lowe, 2016). Literatürde yapılan çalışmalar incelendiğinde, farklı sinıflandırma algoritmaları kullanılarak yapılmış pek çok araştırma mevcuttur.

Huang ve ark. (2002) tarafindan yapilan çalışmada, arazi örtü sınıfları MODIS uydu görüntüsü kullanılarak sınıflandırılmıştır. $\mathrm{Bu}$ işlem için DVM, en yüksek olasıllı, yapay sinir ağları ve karar ağaçları yöntemleri kullanılmıştır. En yüksek başarı DVM 
yöntemi ile elde edilmiş ve ilgili metotların genel sinıflandırma başarıları sırasıyla $\% 75.62, \% 71.76, \% 74.02$ ve \%73.31'dir. Kavzoğlu ve Çölkesen (2010) yaptıkları çalışmada, Landsat ETM+ uydu görüntüsü kullanarak 6 farklı arazi örtü tipi için sınıflandırma işlemi gerçekleştirmişlerdir. Sinıflandırmada, en yüksek olasılık ve DVM'nin polinom, normalleştirilmiş polinom, radyal ve Pearson VII fonksiyonları kullanılmıştır. En iyi sonucu DVM'nin Pearson VII fonksiyonu vermiştir (kappa değeri $=0.94, \quad$ genel siniflandirma başarısı=\%94.83). Çölkesen ve ark. (2016) tarafından yapılan başka bir çalışmada, arazi kullanım sınıflarının ayırt edilmesine yönelik sınıflandırma yapılmış ve sınıflandırma sonucunda $\quad \% 90.46^{\prime} l 1 \mathrm{k}$ bir genel sınıflandırma başarısı elde edilmiştir.

$\mathrm{Bu}$ çalışmada, Landsat 8 uydu görüntüsü kullanilarak, kontrollü siniflandırma algoritmalarından en yüksek olasılık metodu ve DVM'nin doğrusal, polinom, radyal ve sigmoid kernel fonksiyonları kullanılarak arazi kullanım sinifları belirlenmeye çalışılmıştır. Yapılan sınıflandırma işlemi sonucunda performans ölçütleri ortaya konulmuş, en yüksek olasılık metodu ile en iyi sonucu veren DVM fonksiyonuna ilişkin konumsal başarı analizi yapılmış ve karşılaştırılmıştır.

\section{Materyal ve Metot}

Çalışmada, 2013 yılında yapılan envanter çalışması sonucunda üretilen meşcere haritası ve 01.09.2015 Landsat 8 uydu görüntüsü materyal olarak kullanılmıştır.

\section{Çalışma alanı}

$\mathrm{Bu}$ çalışma, Kastamonu Orman Bölge Müdürlüğü, Samatlar Orman İşletme Müdürlüğ̈̈'ne bağlı Kartalsuyu Orman İşletme Şefliği için gerçekleştirilmiştir (Şekil 1). Planlama biriminin toplam alan1 16084.9 ha'dır. Bu alanın 11406.1 ha'lık bölümü (\%70.8) ormanlarla kaplıdır ve önemli bir bölümü $\quad(\% 39.5)$ ibreli ağaçlardan oluşmaktadır (Anonim 2014).

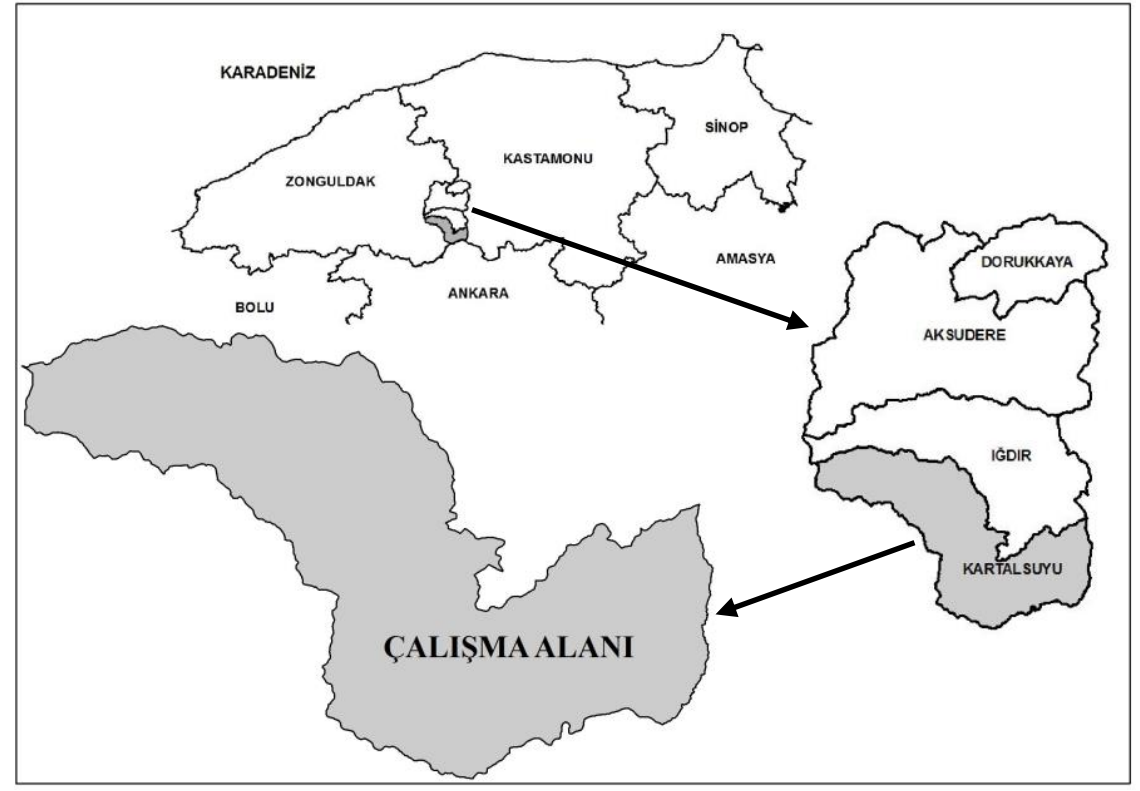

Şekil 1. Kartalsuyu Orman İ̉sletme Şefliği coğrafi konumu

Kartalsuyu Orman İşletme Şefliği, coğrafi olarak Batı Karadeniz bölgesinde, Kastamonu ilinin Araç ilçesi sınırları içerisinde yer almaktadır. Bölgenin en yüksek noktası Görlez mevkii olup rakımı 1744 metredir. En düşük yükseltisi ise 415 metre ile planlama biriminin güney sınırında yer almaktadır. İlgili planlama birimi Ekvator'a göre $41^{\circ} 03^{\prime} 07^{\prime \prime}-41^{\circ} 11^{\prime} 46^{\prime \prime}$ kuzey enlemleri ile Greenwich'e göre $32^{\circ} 55^{\prime} 53^{\prime \prime}-33^{\circ} 13^{\prime} 02^{\prime \prime}$ doğu boylamları arasindadır (Anonim 2014).

\section{Görüntü sınıflandırma}


Bir uydu görüntüsünün sinıflandırılmasında kullanılabilecek çok sayıda yazılım ve yöntem bulunmaktadır. $\mathrm{Bu}$ çalışmada yapılan sınıflandırma işlemleri ENVI 5.2 yazılımı ile gerçekleştirilmiştir. Kullanılan metotlar ise en yüksek olasılık ve destek vektör makinelerinin (DVM) doğrusal, polinom, radyal ve sigmoid kernel fonksiyonlarıdır. Sınıflandırma işleminde referans veri olarak meşcere haritası kullanılmıştır. Burada referans veri olarak kullanılan meşcere haritası doğru olarak kabul edilmiştir. Meşcere haritasından yararlanılarak, arazi kullanım sınıfları ibreli orman, yapraklı orman, karışık orman, bozuk orman ve diğer alanlar (Su, İs, Z, OT, Kum) olmak üzere beş farklı sinıfta değerlendirilmiştir. Her bir arazi kullanım sınıfı için, Landsat 8 uydu görüntüsü üzerinden 10 adet eğitim alanı alınmıştır. Eğitim alanlarının homojen ve yeterli büyüklükte olmasına özen gösterilmiştir. $\mathrm{Bu}$ metotların karşılaştırılmasında denklik olması için bütün sınıflandırma işlemlerinde aynı eğitim alanları kullanılmıştır.

\section{En yüksek olasslık metodu}

En yüksek olasilık metodu, uydu görüntülerinin sinıflandırılmasında yaygın kullanımı olan bir kontrollü sinıflandırma tekniğidir. Bu yöntem istatistiksel tabanlı bir siniflandirma algoritması olup, ortalama değerler yanında, varyans ve kovaryans değerlerini de dikkate almaktadır. $\mathrm{Bu}$ değerlendirme aşamasında sınıf kontrol kümelerini oluşturan verilerin normal dağılıma sahip olduğu varsayılmaktadır. Sınıflandırma aşamasında olasılık yoğunluk fonksiyonları hesaplanmaktadir (1) ve sinıflandırılacak pikseller üyelik olasılığı en yüksek olan sınıflara atanmaktadır. Eğer pikseller için hesaplanan sınıflara ait olma olasılık değerleri, öncesinde belirlenen eşik değerinin altında ise ilgili pikseller belirsiz olarak sinıflandırılmaktadır (Myung, 2003;
Çölkesen, 2009; Günlü, 2012; Topaloğlu ve ark., 2016).

$$
\begin{gathered}
P(x)=\ln \left(a_{C}\right)-\left[0.5 x \ln \left(\left|S_{x}\right|\right)\right]- \\
{\left[0.5 x\left(\mathrm{x}-M_{C}\right)^{T} x\left(S_{x}^{-1}\right) x\left(\mathrm{x}-M_{C}\right)\right]}
\end{gathered}
$$

Eşitlikte, $\mathrm{P}$ olasılık değeri, $\mathrm{C}$ örnek bir sinıfi, $x$ aday pikselin ölçüm vektörü, $M$ sinıfin ortalaması, a aday pikselin sinıfa ait olma yüzdesi ve $S_{\mathrm{x}}$ varyans-kovaryans matrisidir.

\section{Destek vektör makineleri}

Kontrollü sınıflandırma algoritmalarından olan DVM, yapısal risk minimizasyonu prensibine ve istatistiksel öğrenme teorisine dayanmaktadır. DVM başlangıçta iki sınıflı doğrusal verilerin sinıflandırılması için tasarlanmış, daha sonra çok sınıflı ve doğrusal olmayan verilerin sinıflandırma problemini çözmek için geliştirilmiş̧ir. DVM'de amaç, iki sınıfı birbirinden ayırabilen en uygun hiper düzlemin elde edilmesidir (Şekil 2).

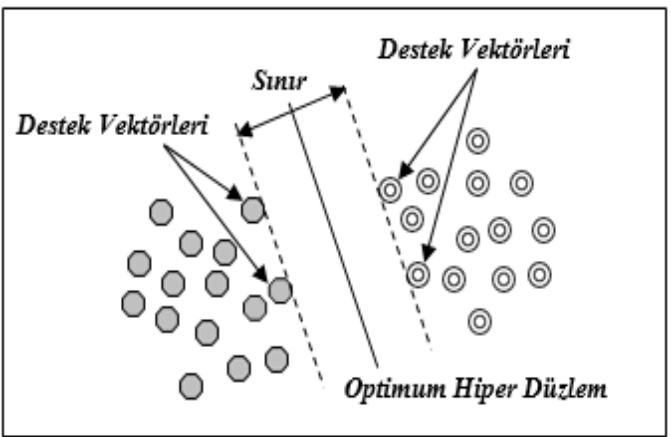

Şekil 2. İki sınıflı bir problemde en uygun hiper düzlem, sınır ve destek vektörleri

Hiper düzlemin sınır genişliğini sonlandıran noktalara destek vektörleri adı verilmektedir. Elde edilen hiper düzlem sayesinde destek vektörleri arasındaki uzaklık maksimize edilmekte ve en uygun karar fonksiyonu oluşturulmaktadır (Kavzoğlu ve Çölkesen, 2010; Hsu ve ark., 2010; Ayhan ve Erdoğmuş, 2014; Kulkarni ve Lowe, 2016).

Tablo 1. Kullanılan kernel fonksiyonlarının matematiksel gösterimi ve en iyi sonucu veren parametre değerleri 


\begin{tabular}{llcccc}
\cline { 3 - 5 } & & $* \mathrm{p}$ & $\mathrm{g}$ & $\mathrm{r}$ & $\mathrm{d}$ \\
\hline Doğrusal Fonksiyon & $\mathrm{K}\left(\mathrm{x}_{\mathrm{i}}, \mathrm{x}_{\mathrm{j}}\right)=\mathrm{x}_{\mathrm{i}}^{\mathrm{T}} \mathrm{x}_{\mathrm{j}}$ & 175 & & & \\
Radyal Fonksiyon & $\mathrm{K}\left(\mathrm{x}_{\mathrm{i}}, \mathrm{x}_{\mathrm{j}}\right)=\exp \left(-\mathrm{g}\left\|\mathrm{x}_{\mathrm{i}}-\mathrm{x}_{\mathrm{j}}\right\|^{2}\right), \mathrm{g}>0$ & 200 & 0.125 & & \\
Polinom Fonksiyon & $\mathrm{K}\left(\mathrm{x}_{\mathrm{i}}, \mathrm{x}_{\mathrm{j}}\right)=\left(\mathrm{gx}_{\mathrm{i}}^{\mathrm{T}} \mathrm{x}_{\mathrm{j}}+\mathrm{r}\right)^{\mathrm{d}}, \mathrm{g}>0$ & 150 & 0.125 & 1 & 5 \\
Sigmoid Fonksiyon & $\mathrm{K}\left(\mathrm{x}_{\mathrm{i}}, \mathrm{x}_{\mathrm{j}}\right)=\tanh \left(\mathrm{gx}_{\mathrm{i}}^{\mathrm{T}} \mathrm{x}_{\mathrm{j}}+\mathrm{r}\right)$ & 150 & 0.125 & 1 & \\
\hline
\end{tabular}

*isteğe bağl1, p: düzenleme parametresi (>0.01), g: gama (>0.01), r: hata (1), d: polinom derecesi (1-6)

DVM kullanilarak yapilacak bir sınıflandırma işleminde farklı kernel fonksiyonları kullanılmaktadır. Her bir kernel fonksiyonu için uygulayıcı tarafindan belirlenmesi gereken farklı parametreler bulunmaktadır (Tablo 1). Çalışmada doğrusal, polinom, radyal ve sigmoid kernel fonksiyonları için bu parametreler farklı değerler kullanılarak beşer kez denenmiştir (Şekil 3). Kullanılan 5 farklı kontrollü sinıflandırma yöntemi, yaygın bir kullanıma sahip olan genel sinıflandırma başarısı ve kappa değeri kullanılarak değerlendirilmiştir. Bunun sonucunda ilgili yöntemlerden en yüksek kappa değerine ve genel sınıflandırma başarısına sahip en iyi iki metot için konumsal başarı analizi yapılmıştır. Bunun için iki metodun uygulaması sonucunda üretilen siniflandırma haritaları vektör veriye çevrilmiștir. Elde edilen vektör katmanları ile meşcere haritası ArcGIS 10.0 yazılımı ile çakıştırılmıştır. Çakıştırma sonucunda konumsal olarak toplam alanın ne kadarının doğru bir şekilde sınıflandırıldığı ortaya konulmuştur.

\section{Bulgular ve Tartışma}

Bu çalışmada, arazi kullanım sınıfları için yapılan sınıflandırma işleminde, en yüksek olasıl1k metodu için kappa değeri 0.81 ve genel sınıflandırma başarısı \%85'tir. DVM doğrusal fonksiyon kullanılarak elde edilen kappa değeri ve genel sınıflandırma başarısı 0.77 ve \%81'dir. Bu değerler sirasıyla DVM radyal fonksiyon için 0.75 ve $\% 80$, DVM polinom fonksiyon için 0.79 ve $\% 84$, DVM radyal fonksiyon için 0.63 ve $\% 71$ 'dir. DVM'nin farklı kernel fonksiyonları için elde edilen bu sonuçlar, yapılan farklı sınıflandırma işlemleri arasından elde edilen en iyi sonuçlardır.

Kulkarni ve Lowe (2016) tarafindan yapılan bir çalışmada Landat 8 uydu görüntüsü kullanılarak arazi örtüsü sınıflaması yapılmıştır. DVM metodu (kappa değeri $=0.99, \quad$ genel siniflandirma başarısı $=\% 99$ ) en yüksek olasılık metoduna (kappa değeri $=0.93$, genel sinıflandırma başarısı $=\% 90$ ) göre daha iyi performans göstermiştir. Topaloğlu ve ark., (2016) Landsat 8 uydu görüntüsüne ek olarak Sentinel 2 uydu görüntüsü de kullanarak arazi örtü sınıflaması yapmışlardır. En iyi sonuç Sentinel 2 uydu görüntüsü ile DVM metodu kullanılarak elde edilmiştir (kappa değeri=0.82, genel siniflandirma başarıs1=\%84). En düşük sonuç ise Landsat 8 uydu görüntüsü ile en yüksek olasılık metodu kullanılarak elde edilmiştir (kappa değeri $=0.66, \quad$ genel siniflandirma başarıs1=\%71). Üstüner ve ark., (2015) RapidEye uydu görüntüsü kullanarak yaptıkları çalışmada en yüksek performansı DVM polinom fonksiyonu ile elde etmişlerdir. En yüksek olasılık metodu, DVM polinom, doğrusal, radyal ve sigmoid fonksiyonlar1 ile sirasiyla $0.7968,0.8411$, $0.8223,0.8222$ ve 0.8209 kappa değerleri elde edilmiştir. Genel sınıflandırma başarıları ise sirasiyla \%81.64, \%85.63, \%83.94, \%83.94 ve $\% 83.82$ 'dir. Taati ve ark., (2014) yaptıkları çalışmada Landsat 5 uydu görüntüsü kullanarak DVM metodu ile 0.82'lik kappa değeri ve \%86.67'lik genel sinıflandırma başarısı, en yüksek olasılık metodu ile de 0.72'lik kappa ve \%80'lik genel sinıflandırma başarısı elde etmişlerdir. 


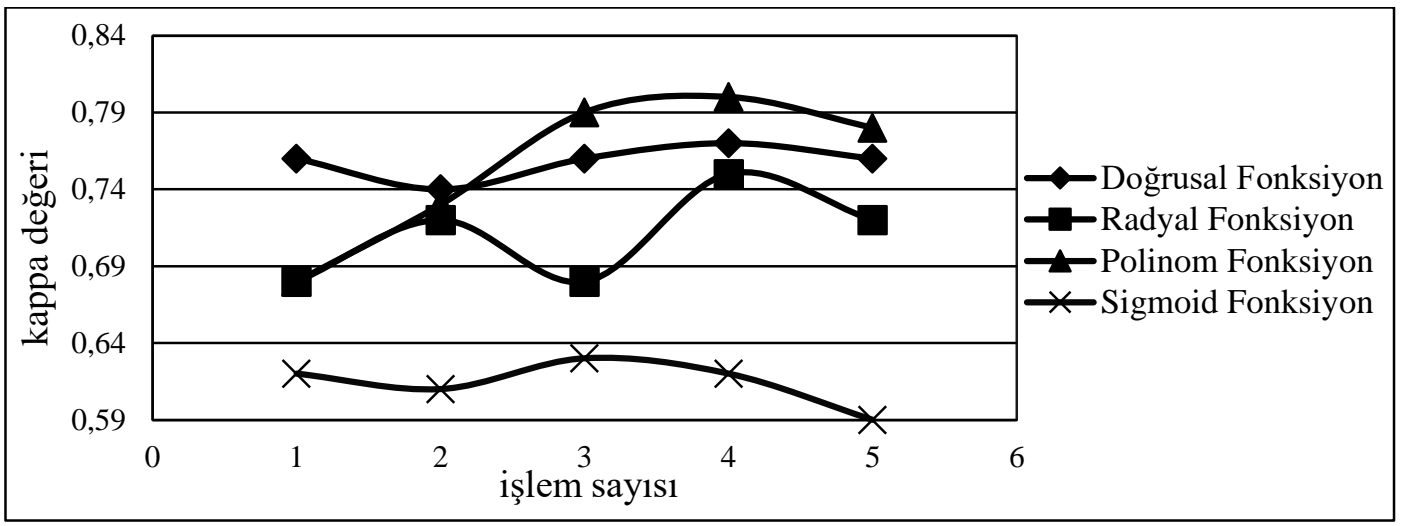

Şekil 3. DVM ile elde edilen farklı fonksiyonlara ait kappa değerleri

$\mathrm{Bu}$ çalışmada uygulanan farklı kontrollü siniflandırma metotları sonucunda en iyi performans1 gösteren metotlar, en yüksek olasılik ve DVM polinom fonksiyonudur. Çalışmada, bu iki metot için konumsal başarı analizi yapılmış, sonuçlar tablo ve haritalar yardımıyla ortaya konulmuştur (Tablo 2-3, Şekil 4-5-6). Buna göre ibreli ormanın meşcere haritasında alan miktarı 6359.63 ha'dır. En yüksek olasilık metodu ile yapılan sinıflandırma sonucunda elde edilen görüntü üzerinde ibreli ormanların alan miktarı 2058.28 ha olup bu alanın 1954.02 ha'1 konumsal olarak doğru bir şekilde sinıflandırılmıştır. DVM polinom fonksiyonu ile yapılan sınıflandırma işleminde ise ibreli ormanlar 2011.02 ha alan kaplamakta ve bu alanın 1895.93 ha'ı doğru sınıflandırılmıştır. $\mathrm{Bu}$ iki metot için ibreli orman sınıfının konumsal sinıflandırma başarıları oldukça benzerdir (\%94.9 ve \%94.3).

Tablo 2. En yüksek olasılık metodu ile meşcere tipi haritası ve Landsat 8 uydu görüntüsünden elde edilen arazi kullanım sınıflarının konumsal analiz sonuçları

\begin{tabular}{|c|c|c|c|c|c|c|c|}
\hline \multirow{2}{*}{$\begin{array}{c}\text { Arazi Kullanım } \\
\text { Sınıfları }\end{array}$} & \multicolumn{2}{|c|}{$\begin{array}{c}\text { Meşcere Tipi } \\
\text { Haritası }\end{array}$} & \multicolumn{2}{|c|}{$\begin{array}{c}\text { Landsat } 8 \text { Uydu } \\
\text { Görüntüsü }\end{array}$} & \multirow{2}{*}{$\begin{array}{c}\text { Farklar } \\
(+/-)\end{array}$} & \multicolumn{2}{|c|}{$\begin{array}{l}\text { Sinıflandırmanın } \\
\text { Konumsal Başarısı }\end{array}$} \\
\hline & ha & $\%$ & ha & $\%$ & & ha & $\%$ \\
\hline İbreli Orman & 6359.63 & 39.5 & 2058.28 & 12.8 & 4301.35 & 1954.02 & 94.9 \\
\hline Yapraklı Orman & 1820.56 & 11.3 & 2057.75 & 12.8 & -237.19 & 724.61 & 35.2 \\
\hline Karışık Orman & 1314.99 & 8.1 & 4344.35 & 27.0 & -3029.66 & 712.21 & 16.4 \\
\hline Bozuk Orman & 1910.68 & 11.9 & 3560.67 & 22.1 & -1649.99 & 1079.70 & 30.3 \\
\hline Diğer Alanlar & 4678.42 & 29.2 & 4063.23 & 25.3 & 615.19 & 3164.89 & 77.9 \\
\hline Toplam & 16084.28 & 100.0 & 16084.28 & 100 & & 7635.43 & 47.5 \\
\hline
\end{tabular}

Tablo 3. DVM polinom fonksiyonu ile meşcere tipi haritası ve Landsat 8 uydu görüntüsünden elde edilen arazi kullanım sınıflarının konumsal analiz sonuçları

\begin{tabular}{|c|c|c|c|c|c|c|c|}
\hline \multirow[t]{2}{*}{$\begin{array}{c}\text { Arazi Kullanım } \\
\text { Sinıfları }\end{array}$} & \multicolumn{2}{|c|}{$\begin{array}{c}\text { Meşcere Tipi } \\
\text { Haritası }\end{array}$} & \multicolumn{2}{|c|}{$\begin{array}{c}\text { Landsat } 8 \text { Uydu } \\
\text { Görüntüsü }\end{array}$} & \multirow{2}{*}{$\begin{array}{c}\text { Farklar } \\
(+/-)\end{array}$} & \multicolumn{2}{|c|}{$\begin{array}{c}\text { Sinıflandırmanın } \\
\text { Konumsal } \\
\text { Başarısı }\end{array}$} \\
\hline & ha & $\%$ & ha & $\%$ & & ha & $\%$ \\
\hline İbreli Orman & 6359.63 & 39.5 & 2011.02 & 12.5 & 4348.61 & 1895.93 & 94.3 \\
\hline Yapraklı Orman & 1820.56 & 11.3 & 3558.19 & 22.1 & -1737.63 & 783.04 & 22.0 \\
\hline Karışık Orman & 1314.99 & 8.1 & 3445.68 & 21.4 & -2130.69 & 624.24 & 18.1 \\
\hline Bozuk Orman & 1910.68 & 11.9 & 3669.74 & 22.8 & -1759.06 & 985.53 & 26.9 \\
\hline Diğer Alanlar & 4678.42 & 29.2 & 3399.65 & 21.2 & 1278.77 & 2681.72 & 78.9 \\
\hline Toplam & 16084.28 & 100.0 & 16084.28 & 100 & & 6970.46 & 43.3 \\
\hline
\end{tabular}


Yapraklı orman sınıfı için en yüksek olasıllk metodu ile elde edilen görüntüde alan miktarı 2057.75 ha'dır ve bu alanın 724.61 ha'ı doğru olarak sınıflandırılmıştır. Bu sınıf için elde edilen konumsal sinıflandırma başarıs1 \%35.2'dir. DVM polinom fonksiyonu için ise oluşturulan 3558.19 ha'lk yapraklı orman sinıfından 783.04 ha'lık kısmı doğru sınıflandırılmıştır. Bu durumda elde edilen konumsal sınıflandırma başarısı \%22'dir. DVM polinom fonksiyonu daha fazla miktarda alanı doğru sınıflandırmıştır. Fakat bunu sınıf alanına oranladığımızda sınıflandırma başarısı DVM metodu için daha düşük çıkmaktadır.

Karşılaştırılan iki metot için konumsal sınıflandırma başarısına ait en yüksek fark yapraklı orman sınıfi için elde edilmiştir (\%13.2). Karışık orman ve diğer alanlar sınıfı için DVM polinom fonksiyonu daha başarılı bulunmuştur. Diğer sınıflar için en yüksek olasılık metodu daha başarılı olmakla birlikte genel olarak elde edilen konumsal başarı oranları oldukça benzerdir. En düşük başarı, en yüksek olasılık metodu ile \%16.4, DVM polinom fonksiyonu ile \%18.1 konumsal sınıflandırma başarısı olmak üzere karışık orman sınıfı için elde edilmiştir. En yüksek başarı, en yüksek olasılık metodu ile \%94.9, DVM polinom fonksiyonu ile \%94.3 olmak üzere ibreli orman sınıfı için elde edilmiştir. Genel başarı yüzdesine bakıldığında ise en yüksek olasilık metodu konumsal olarak alanın \%47.5'ini, DVM polinom fonksiyonu ise \%43.3'ünü doğru bir şekilde sinıflandırmıştır.

Araştırma konusu ile ilgili olarak yapılan benzer çalışmalar incelendiğinde; Günlü ve ark., (2008) Landsat 7 ETM uydu görüntüsü kullanarak arazi örtü tipini sınıflandırmışlar ve \%61.7'lik konumsal sınıflandırma başarısı elde etmişlerdir. Günlü ve ark., (2011) yaptıkları farklı bir çalışmada konumsal analiz sonuçlarına göre arazi kullanım sınıfları için \%45.5 oranında sınıflandırma başarısı elde etmişlerdir. Günlü (2012) tarafından yapılan başka bir çalıșmada ise arazi kullanım sınıfları için konumsal sınıflandırma başarısı \%58.6 bulunmuştur.

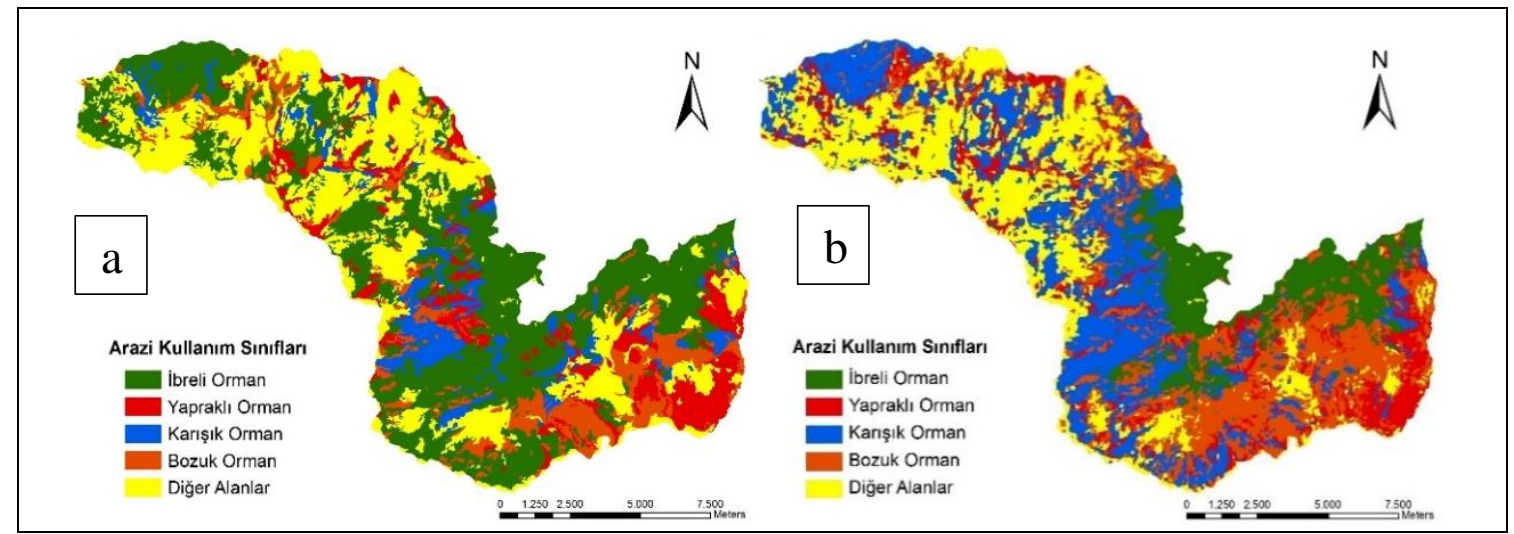

Şekil 4. Arazi kullanım sınıfları a) meşcere tipi haritası b) Landsat8 uydu görüntüsü (en yüksek olasıl1k metodu)

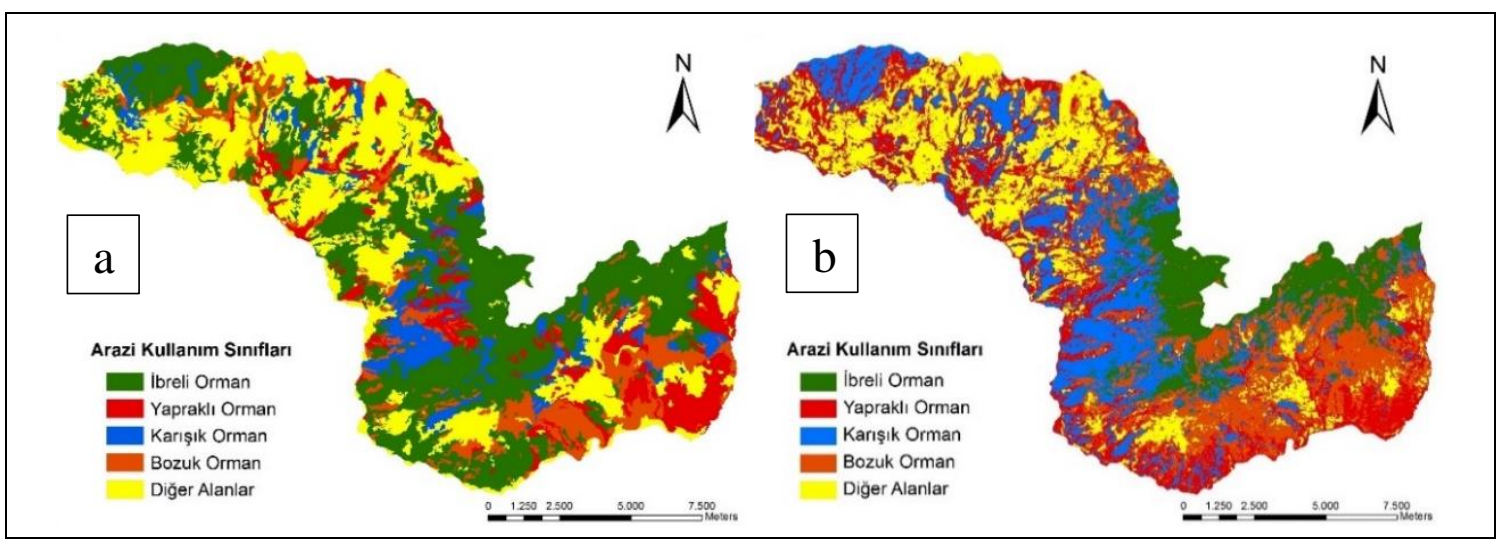


Şekil 5. Arazi kullanım sınıfları a) meşcere tipi haritası b) Landsat8 uydu görüntüsü (DVM polinom fonksiyonu)

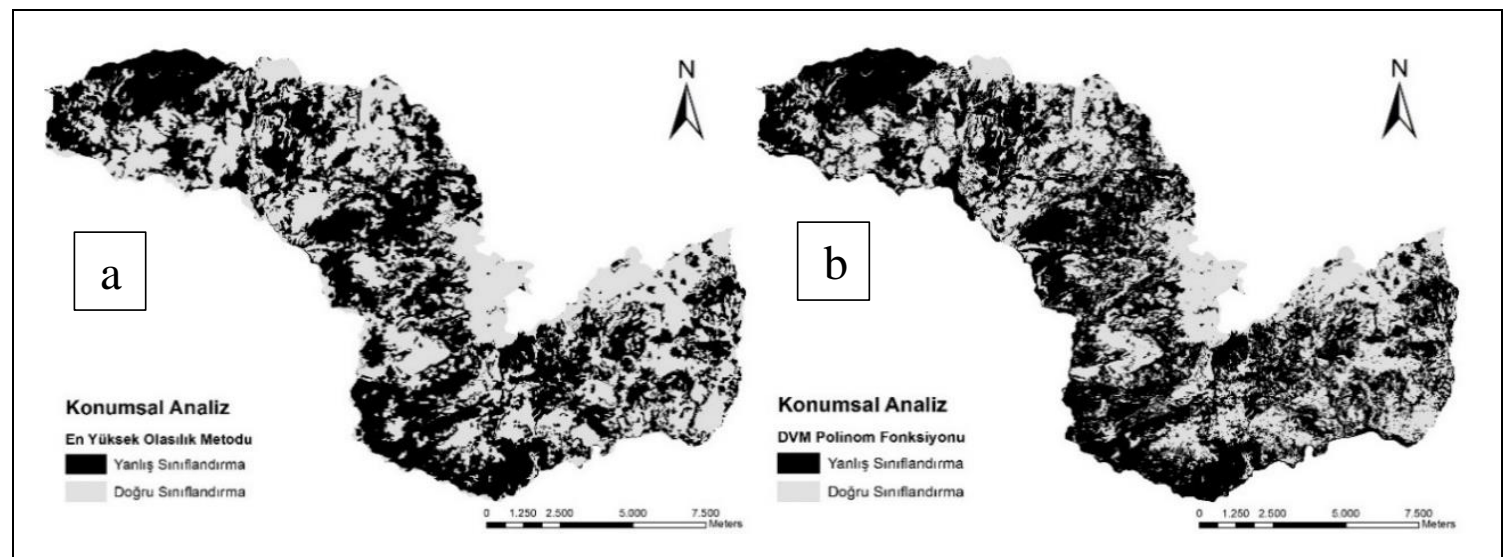

Şekil 6. Konumsal analiz başarı haritası a) en yüksek olasılık metodu b) DVM polinom fonksiyonu

\section{Sonuc}

Bu çalışmada en yüksek olasıllık ve destek vektör makinelerinin (DVM) doğrusal, polinom, radyal ve sigmoid kernel fonksiyonlar1 kullanılarak kontrollü sınıflandırma işlemi gerçekleștirilmiştir. Yapılan siniflandirma sonucunda bütün metotlar kappa değeri ve genel sinıflandırma başarısı baz alınarak değerlendirilmiş ve en iyi sonuç veren en yüksek olasilık metodu ve DVM polinom fonksiyonu için konumsal başarı analizi yapılarak değerlendirilmiştir.

Elde edilen sonuçlara göre en yüksek olasılık metodu kappa değeri, genel sınıflandırma başarısı, konumsal başarı ve kullanım kolaylığı açısından daha avantajlı görülmüştür. Fakat yapılan farklı çalışmalara bakıldığında DVM ile yapılan sınıflandırma işlemlerinde göz ardı edilmeyecek seviyede iyi sonuçlar elde edilmektedir. Bundan dolayı bu tür çalıșmaların yaygınlaştırılması, daha yüksek çözünürlükte uydu görüntülerinin kullanılması, özellikle sinıflandırma işlemlerinde eğitim alanlarının daha fazla sayıda ve hassas bir şekilde alınması uygulanan metotların performansı açısından daha doğru bilgi edinilmesini sağlayacaktır.

\section{Teșekkür}

$\mathrm{Bu}$ çalışmada kullanılan meşcere haritalarının temini için Orman Genel Müdürlüğü, Orman İdaresi ve Planlama Daire Başkanlığına teşekkür ederiz.

\section{Kaynaklar}

Anonim 2014. Kastamonu Orman Bölge Müdürlüğü, Samatlar Orman İșletme Müdürlüğü, Kartalsuyu Orman İşletme Şefliği fonksiyonel orman amenajman planı. T.C. Orman ve Su İşleri Bakanlığı, Orman Genel Müdürlüğü, 373 s., Kastamonu.

Ayhan S., Erdoğmuş Ş. 2014. Destek vektör makineleriyle siniflandirma problemlerinin çözümü için çekirdek fonksiyonu seçimi. Eskişehir Osmangazi Üniversitesi, İ̈BF Dergisi, 9(1):175-198.

Cölkesen İ. 2009. Uzaktan algılamada ileri sınıflandırma tekniklerinin karşılaştırılması ve analizi. Yüksek Lisans Tezi, GYTE Mühendislik ve Fen Bilimleri Enstitüsü, 153 s. Gebze.

Çölkesen İ, Sahin E.K., Kavzoglu T. 2016. Susceptibility mapping of shallow landslides using kernel-based Gaussian process, support vector machines and logistic regression. Journal of African Earth Sciences, 118,53-64.

Günlü A., Sivrikaya F., Başkent E.Z., Keleş S., Çakır G., Kadığullari A.İ. 2008. Estimation of stand type parameters and land cover using Landsat-7 ETM image: a case study from Turkey, Sensors 2008, 8, 2509-2525.

Günlü A., Keleş S., Kadıoğullari A.İ., Başkent E.Z. 2011. Landsat 7 ETM+ uydu görüntüsü yardimiyla arazi kullanimi, meşcere gelişim çaği ve meşcere kapaliliğin tahmin edilmesi; Kastamonu-Kızılcasu İşletme Şefliği örneği. I. Ulusal Akdeniz Orman ve Çevre Sempozyumu (26-28 Ekim 2011), 660-667, Kahramanmaraş, Türkiye.

Günlü A. 2012. Landsat TM uydu görüntüsü yardımıyla bazı meşcere parametreleri (gelişim çağı ve kapalılık) ve arazi kullanım sınıflarının 
belirlenmesi. Kastamonu Üniversitesi, Orman Fakültesi Dergisi, 12(1):71-79.

Hsu C.W., Chang C.C., Lin C.J. 2010. A practical guide to support vector classification. National Taiwan University. http://ntu.csie.org/ cjlin/papers/guide/ guide.pdf

Huang C., Davis L.S., Townshend J.R.G. 2002. An assessment of support vector machines for land cover classification. International Journal of Remote Sensing, 23(4),725-749.

Kavzoğlu T., Çölkesen İ. 2010. Destek vektör makineleri ile uydu görüntülerinin sınıflandirılmasında kernel fonksiyonlarının etkilerinin incelenmesi. Harita Dergisi, Temmuz 2010, 144:73-82.

Kulkarni A.D., Lowe B. 2016. Random forest algorithm for land cover classification. Computer Science Faculty Publications and Presentations. Paper 1. htp://hdl.handle.net/10950/341.

Myung I.J. 2003. Tutorial on maximum likelihood estimation. Journal of Mathematical Psychology, 47:90-100.

Otukei J., Blaschke T. 2010. Land cover change assessment using decision trees, support vector machines and maximum likelihood classification algorithms. Int $\mathbf{J}$ Appl Earth Obs Geoinf 12:S27-S31.

Srivastava P.K., Han D., Rico-Ramirez M.A., Bray M., Islam T. 2012. Selection of classification techniques for land use/land cover change investigation. Adv Space Res 50(9):1250-1265.

Taati A., Sarmadian F., Mousavi A., Pour C.T.H., Shahir A.H.E. 2014. Land use classification using support vector machine and maximum likelihood algorithms by Landsat 5 TM images. Walailak Journal of Science and Technology, 12(8): 681-687.

Topaloğlu R.H., Sertel E., Musaoğlu N. 2016. Assessment of classification accuracies of Sentinel-2 and Landsat-8 data for land cover / use mapping. The International Archives of the Photogrammetry, Remote Sensing and Spatial Information Sciences, Volume XLI-B8, 2016, XXIII ISPRS Congress, 12-19 July 2016, Prague, Czech Republic.

Üstüner M., Şanlı F.B., Dixon B. 2015. Application of support vector machines for landuse classification using high-resolution RapidEye images: a sensitivity analysis. European Journal of Remote Sensing, 48: 403-422. 